\title{
APPLICATION OF A NEW SAND TRANSPORT FORMULA WITHIN THE CROSS-SHORE MORPHODYNAMIC MODEL UNIBEST-TC
}

\author{
Jebbe van der Werf ${ }^{1,3}$, Harm Nomden ${ }^{2}$, Jan Ribberink ${ }^{3}$, Dirk-Jan Walstra ${ }^{1}$, Wouter \\ Kranenburg ${ }^{3}$
}

\begin{abstract}
In this paper, we have implemented and tested the new SANTOSS sand transport formula with the cross-shore morphodynamic model UNIBEST-TC using data from the LIP and Grasso wave flume experiments. It is shown that the total net sand transport is a delicate balance between wave- and current-related transport in the wave boundary layer (which can be on- or offshore-directed) and offshore-directed current-related suspended load above it. The change from onshore to offshore net transport for the two Grasso cases was reproduced by the SANTOSS model and seems to be due to the increasing importance of phase-lags between intra-wave velocities and sand concentrations. More generally, measured net sand transport rates are reasonably well reproduced by the SANTOSS formula outside the surf zone if orbital velocities and ripple heights are predicted correctly and phase-lags between velocities and suspended sand concentrations are accounted for.
\end{abstract}

Keywords: morphodynamic modeling; sand transport; sand transport formulas; wave flume experiments; waves

\section{INTRODUCTION}

Coastal engineers use morphological modeling systems to understand and predict coastal erosion and sedimentation due to natural processes and anthropogenic activity, and as such these modeling systems play a crucial role in design and management decisions for the coastal zone. This includes the assessment of the impact of climate change, through increased storminess and rising sea levels, on beach stability, the integrity of coastal structures and the design of nourishment schemes.

Morphological modeling systems have serious restrictions since the underlying sub-models (especially for the sediment transport) are subject to strong parameterization and scale limitations. For example, Van Rijn et al. (2011) have recently showed that cross-shore accretion events of beaches can still not be represented adequately with the present morphological modeling systems.

This triggered the SANTOSS research project in which a new practical model for sand transport induced by non-breaking waves, non-breaking waves with currents and currents alone was developed (Van der A et al., 2010). The model has been developed and calibrated on the basis of a large dataset of measured net transport rates for a wide range of hydrodynamic and sand conditions typical for coastal areas. The formula is semi-unsteady based on the half-wave cycle concept. It accounts for all transport modes (wave- and current-related bedload and suspended load) within the wave boundary layer, incorporating effects of wave skewness, wave asymmetry, specific surface wave effects (advection, boundary layer streaming) and phase-lag effects (fine sediments, ripple regime). For steady flow the model accounts for bedload only.

This paper describes the next step to practical application. We have implemented the SANTOSS formula within the cross-shore morphodynamic model UNIBEST-TC (Ruessink et al., 2007), and tested it against two sets of wave flume experiments: the LIP and Grasso experiments. UNIBEST-TC comprises coupled, wave-averaged equations of hydrodynamics (waves and mean currents), sediment transport, and bed level evolution. Straight, parallel depth contours are assumed throughout.

In this paper we will intercompare the sand transport computed by the Van Rijn (2007ab) and the SANTOSS formula, both within the framework of UNIBEST-TC. The Van Rijn formula distinguishes between bedload and wave-related suspended load incorporating effects of wave skewness and asymmetry, boundary layer streaming and phase-lag effects. The current-related suspended load follows from the mean concentration and velocity profiles computed by the 1DV advection-diffusion and flow solvers of UNIBEST-TC.

The sand transport calculation with the SANTOSS formula within UNIBEST-TC is slightly different. The SANTOSS model describes the total load within the wave boundary layer, which includes current-related suspended load. The current-related suspended load above the wave boundary layer is computed in the same way as for the Van Rijn implementation, but now the vertical

\footnotetext{
${ }_{1}^{1}$ Deltares, The Netherlands. E-mail addresses: jebbe.vanderwerf@deltares.nl, dirkjan.walstra@deltares.nl

${ }^{2}$ RoyalHaskoningDHV, The Netherlands. E-mail address: harm.nomden@dhv.com

${ }^{3}$ University of Twente, The Netherlands. E-mail addresses: j.s.ribberink@utwente.nl, w.m.kranenburg@utwente.nl
} 
integration starts at the edge of the wave boundary layer instead of the edge of the bedload layer (see Nomden, 2011 for more details). There is little known on the wave-related suspended load under breaking wave conditions. Given the high levels of suspension and the horizontal and vertical advection of momentum and sand, it seems possible that there is a wave-related suspended load component present above the wave boundary layer. This transport component is currently not accounted for by the SANTOSS model.

In both cases (Van Rijn and SANTOSS) the orbital velocities are computed using the expression of Ruessink et al. (2012) for velocity skewness and asymmetry, which are transformed into a timeseries using the method of Abreu et al. (2010) (see Nomden, 2011). Bed slope effects on sand transport are also accounted for using the existing expressions within UNIBEST-TC.

\section{APPLICATION TO THE LIP CASES}

\section{LIP experiments}

The LIP experiments were carried out in the $240 \mathrm{~m}$ Delta Flume of Delft Hydraulics (now Deltares) (Roelvink and Reniers, 1995). During these experiments water levels, wave-averaged velocity and suspended concentration profiles, orbital velocities and bed levels were measured. We have investigated the LIP 1B case, an erosive test with offshore bar movement and "offshore" wave height $H_{m 0}=1.4 \mathrm{~m}$ and spectral peak period $T_{p}=5 \mathrm{~s}$, and the LIP $1 \mathrm{C}$ case, an accretive test with onshore bar movement and offshore $H_{m 0}=0.6 \mathrm{~m}$ and $T_{p}=8 \mathrm{~s}$. The median grain size was $0.22 \mathrm{~mm}$.

\section{Estimation net sand transport rates from experiments}

The measured wave-averaged vertical velocity and concentration profiles allow us to estimate the current-related suspended load by taking the vertical integral of the product of these two. In this way we can make a direct comparison between measured and computed current-related suspended load above the wave boundary layer, next to the total sand transport based on measured bed levels (see later on).

In order to do so we fitted a Rouse profile to the sediment concentrations:

$$
\langle c(z)\rangle=c_{a}\left(\frac{z_{a}}{z}\right)^{\alpha}
$$

with $c_{a}$ the reference concentration at $z=z_{a}(=0.01 \mathrm{~m}), z$ the elevation above the bed and $\alpha$ the concentration decay parameter. Furthermore, we linearly interpolated the velocity profile adding a point at the bed: $\langle u\rangle=0 \mathrm{~m} / \mathrm{s}$ at $z=0 \mathrm{~m}$. The current-related suspended load above the boundary layer then follows from:

$$
\left\langle q_{s c}\right\rangle=\int_{\delta_{w}}^{z_{w}}\langle u\rangle\langle c\rangle d z
$$

with $\delta_{w}$ the edge of the wave boundary layer and $z_{w}$ the water level. We compute the wave boundary layer thickness using the expression of Sleath (1987):

$$
\frac{\delta_{w}}{k_{s w}}=0.27\left(\frac{a}{k_{s w}}\right)^{0.67}
$$

with $k_{s w}$ the wave-related bed roughness and $a$ the orbital excursion amplitude. For the LIP 1B experiments the computed wave boundary layer thickness for most locations varied between 0.02 and $0.03 \mathrm{~m}$ and for the LIP $1 \mathrm{C}$ experiments between 0.04 and $0.05 \mathrm{~m}$; we took $0.03 \mathrm{~m}$ and $0.05 \mathrm{~m}$ as the lower integration boundary to compute the current-related suspended load according to Eq. (2).

As an example, Figure 1 shows the measured and fitted profiles of the wave-averaged velocities, suspended sand concentrations and sand fluxes just offshore and onshore the breaker bar for LIP 1B. This figure shows that the Rouse profile fits the measured concentrations well. In both cases the net suspended load above the wave boundary layer is offshore-directed (negative) due to the undertow. Wave breaking on and just onshore the breaker bar resulted into strong undertow and high suspended sand concentrations leading to relatively large offshore-directed net suspended load. 

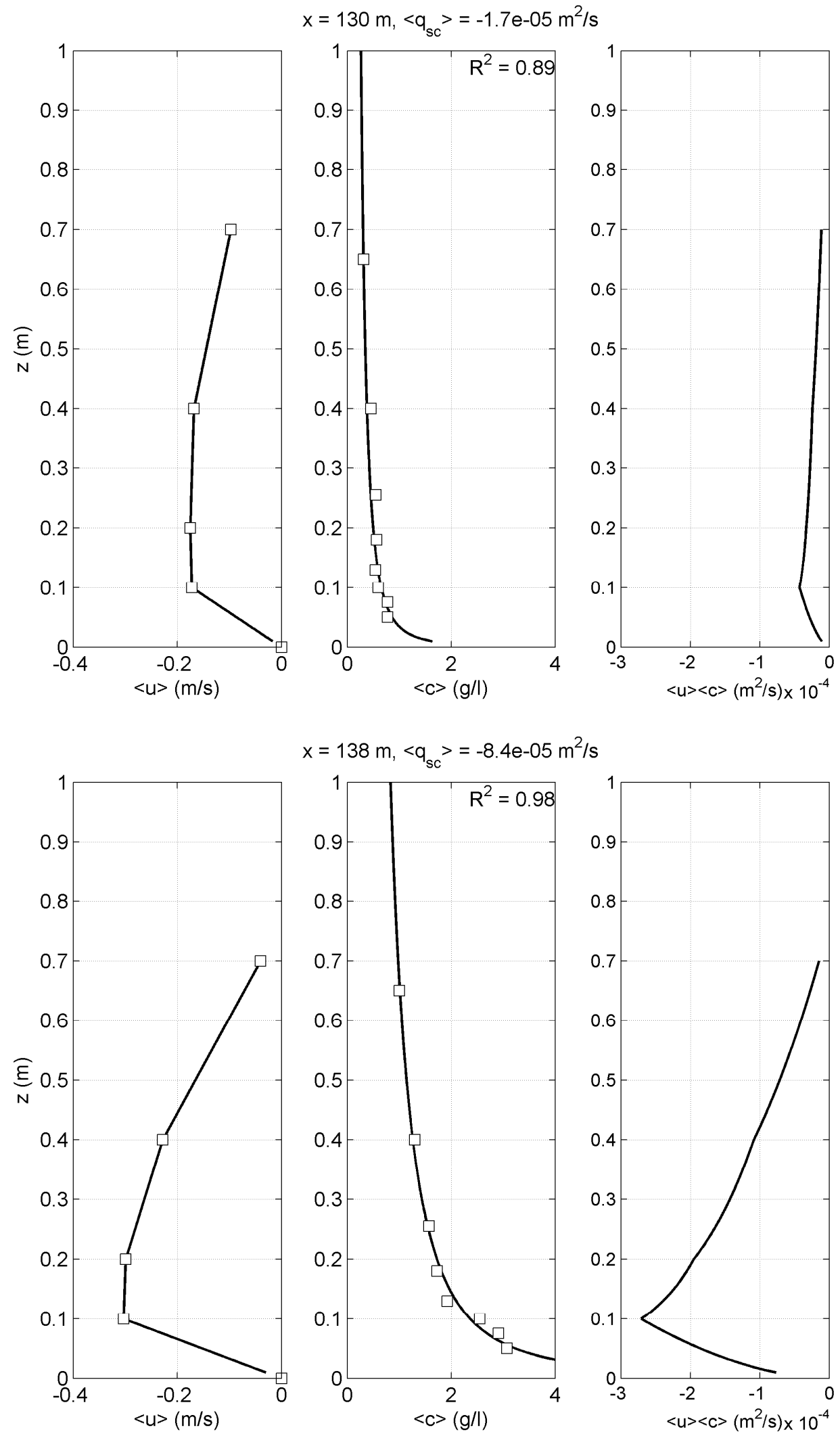

$\mathrm{x}=138 \mathrm{~m},<\mathrm{q}_{\mathrm{sc}}>=-8.4 \mathrm{e}-05 \mathrm{~m}^{2} / \mathrm{s}$
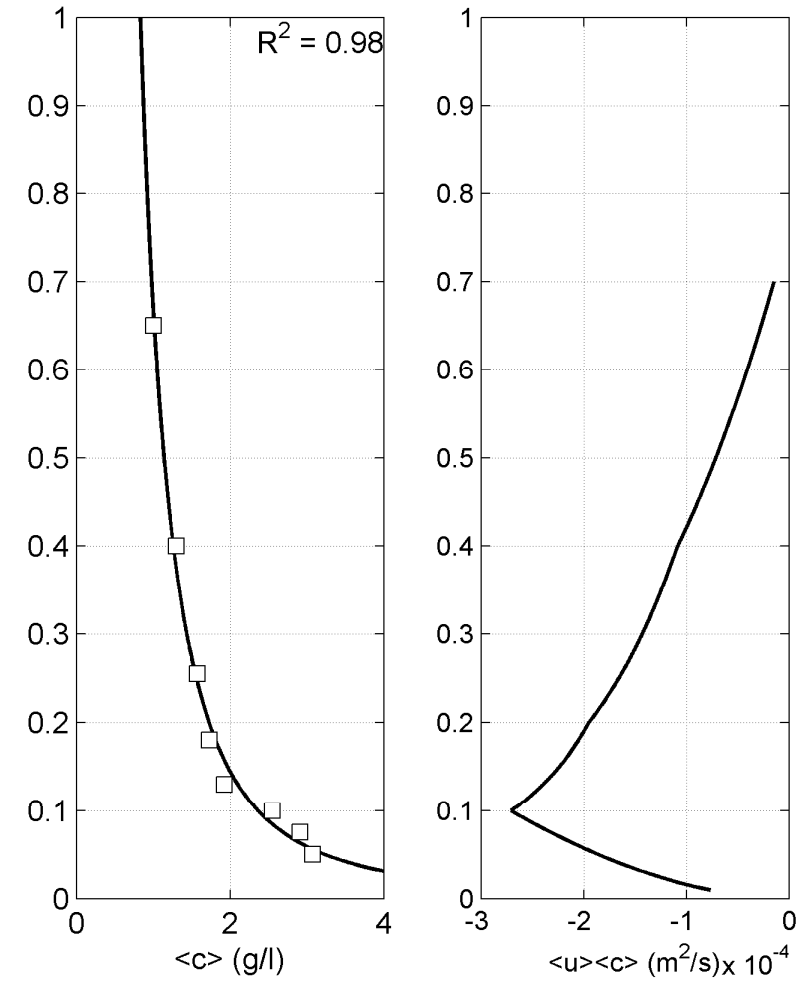

Figure 1. Measured (squares) and fitted (solid lines) wave-averaged velocity (left), suspended concentration (middle) and sand flux (right) profiles just offshore (upper) and onshore (lower) the breaker bar for LIP 1B. 
The near-bed transport, including wave- and current-related bedload and suspended load, is defined by $\left\langle q_{n b}\right\rangle=\left\langle q_{t o t}\right\rangle-\left\langle q_{s c}\right\rangle$ with $\left\langle q_{t o t}\right\rangle$ the total net transport, which follows from integration of the mass balance equation based on measured bed levels before and after the experiment. This is done assuming zero net transport at the left and right bed boundary and a bed porosity of 0.4. The difference between the two is an indication of measurement inaccuracies and loss of sand in longitudinal and lateral direction.

\section{Model-data comparison}

Figure 2 shows that by calibration the computed wave heights agree well with the measurements. The lower panels show the bed level evolution. Figure 3 compares measured and computed significant on- and offshore orbital velocities $U_{\text {sig,on }}$ and $U_{\text {sig,off }}$ and velocity skewness parameter $R$ defined as follows:

$$
R=\frac{U_{s i g, o n}}{U_{s i g, o n}+U_{s i g, o f f}}
$$

The Ruessink et al. - Abreu approach works reasonably well for LIP 1B. The measured velocity skewness is larger for LIP 1C than for LIP 1B, which is not followed by the model results. Velocity skewness parameter $R$ is strongly underpredicted for LIP 1C (too low $U_{\text {sig,on }}$ and too high $U_{\text {sig,off }}$ ), especially close to the shore.

A comparison between measured and computed (not calibrated) vertical profiles of wave-averaged velocity and suspended sand concentrations can be found in Nomden (2011). This comparison showed that undertow profiles are reasonably well predicted, but with an overprediction onshore of the breaker bar for LIP 1B. The concentration profiles were overpredicted for both test cases at almost all crossshore locations.

Figure 4 compares measured and computed net transport rates. This includes the SANTOSS as well as the Van Rijn (2007ab) sand transport formula.

The uncertainty in the LIP 1C net transport measurements is quite large, as can be seen by the difference between assuming zero transport at the left (solid lines) or right (dashed lines) bed boundary. For LIP 1B the difference is much smaller. The measurements show that the near-bed transport is typically onshore-directed due to wave skewness and wave asymmetry, whereas currentrelated suspended load above the wave boundary layer is offshore-directed due to undertow, and that the total net transport is a delicate balance between these two. Both transport components have their peak at the breaker bar, where wave breaking generates large amounts of suspended sand. For the erosion test case LIP 1B the near-bed transport is dominant offshore from the breaker bar, while the undertow transport dominates from the breaker bar onshore. Wave breaking is less intense for test case LIP 1C due to the lower wave height, and as a result net transport is onshore-directed along the profile, due to the dominant near-bed transport.

The current-related suspended load above the wave boundary layer is generally overpredicted due to too large velocity and concentration values. The SANTOSS and Van Rijn formulas give similar results for the near-bed transport. They do reasonably well offshore the breaker bar for LIP 1B. The agreement with the data is worst close to the breaking point (although the near-bed transport peak is picked up by the SANTOS formula to a certain degree), which reflects the fact that these transport models are mainly developed for and tested against data for non-breaking wave conditions. The SANTOSS and Van Rijn formulas do not perform well for LIP 1C. The increase in transport rate with distance from the wave board is not reproduced, which is related to the underprediction of the velocity skewness (see Figure 3). This stresses the importance of a good method to compute orbital velocity time series. 

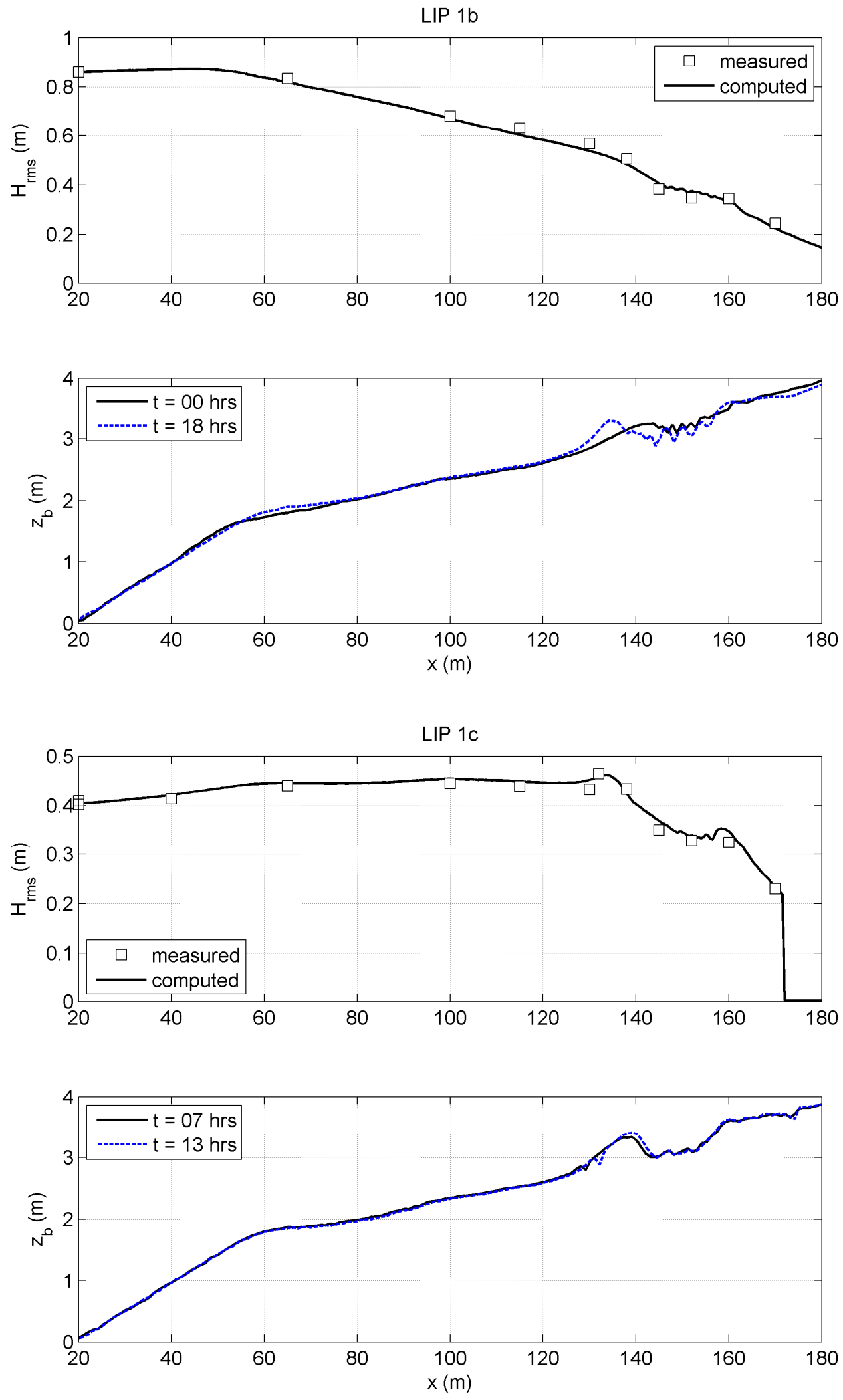

Figure 2. Measured (squares) and computed (solid lines) wave heights for LIP 1B (upper) and LIP 1C (lower). Also shown are the bed level measurements that were used to determine the measured net transport rates. 

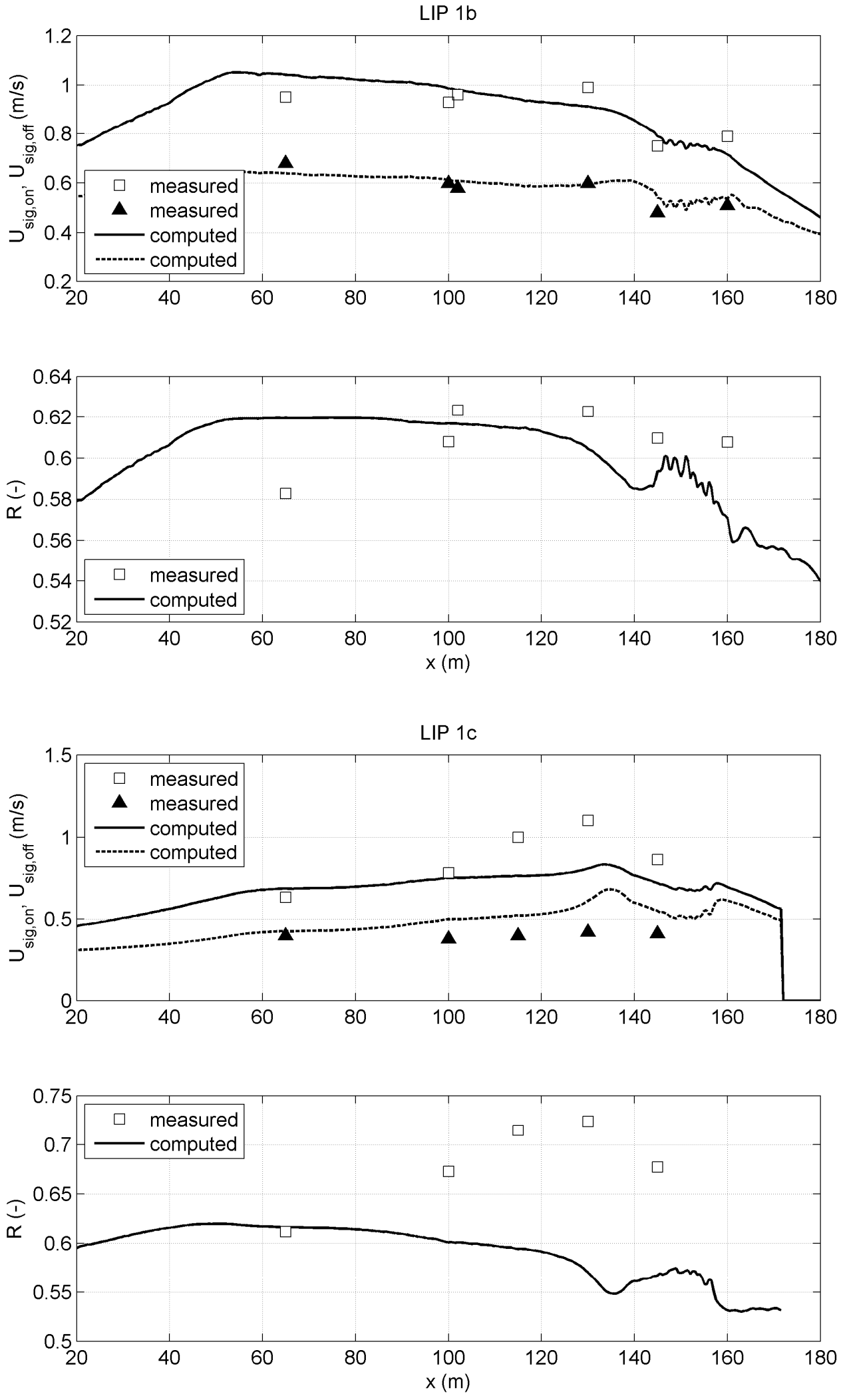

Figure 3. Measured (squares and triangles) and computed (solid and dashed lines) orbital velocity amplitudes

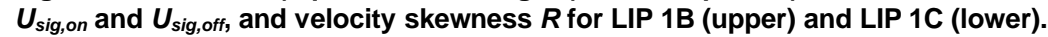



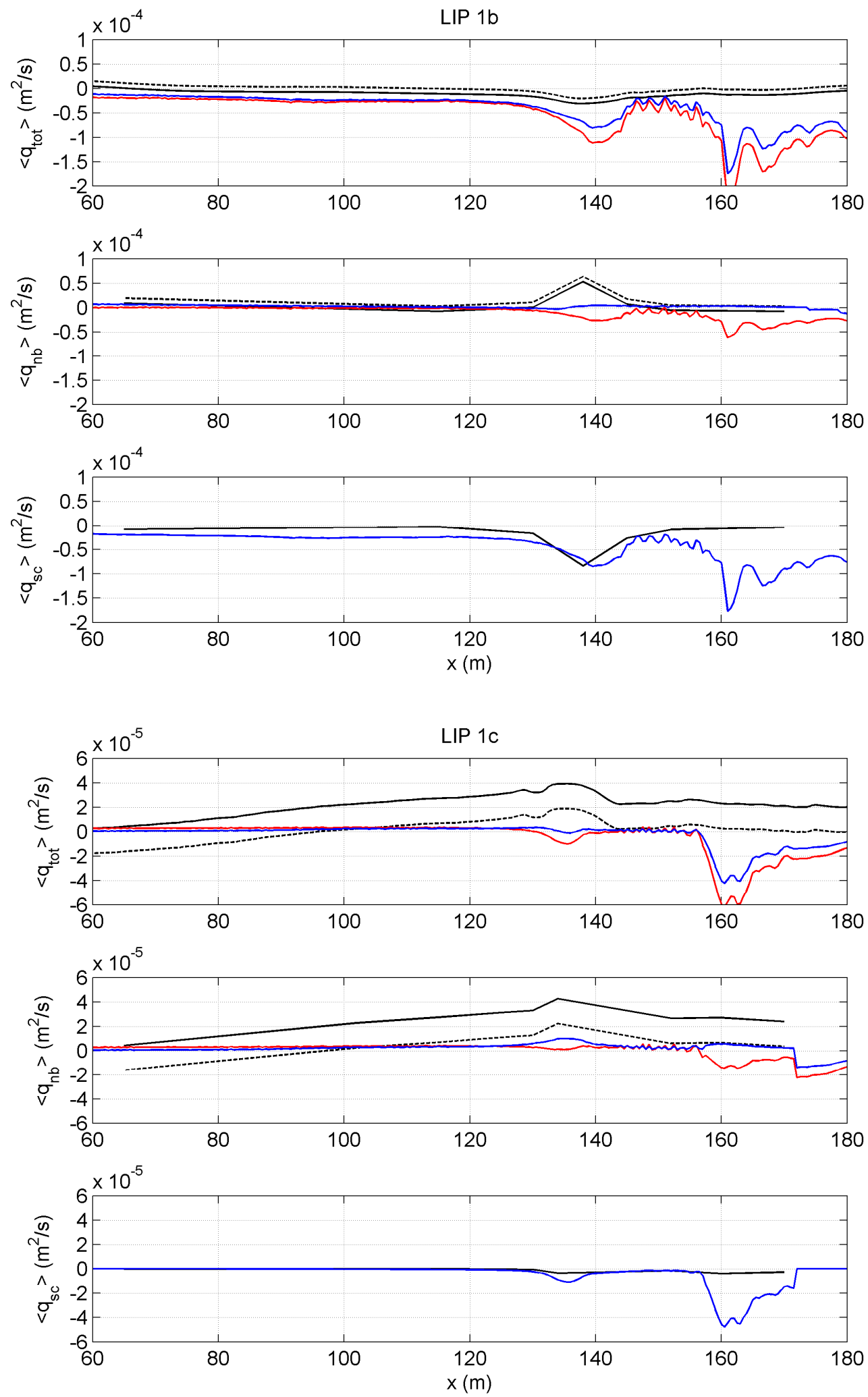

Figure 4. Comparison between measured and computed total (upper panels), near-bed (middle panels) and current-related suspended above the wave boundary layer (lower panels) transport for LIP 1B (upper figure) and LIP 1C (lower figure). Solid black lines: based on the total net transport from integration mass balance equation from the right side; dashed black lines: based on the total net transport from integration mass balance equation from the left side; red lines: computed by the Van Rijn formula; blue lines: computed by the SANTOSS formula. 


\section{APPLICATION TO THE GRASSO CASES}

\section{Grasso experiments}

Our second set of tests comprises tests of the Grasso experiments, which were carried out in the $36 \mathrm{~m}$ long LEGI wave flume (Grasso et al., 2011). The still water depth at the wave maker was 0.55 $\mathrm{m}$. The sloping bottom consisted of low density sediment $\left(1190 \mathrm{~kg} / \mathrm{m}^{3}\right)$ with a median diameter of $0.64 \mathrm{~mm}$. The Froude number, the Shields number and the Rouse number are of the same magnitude as those of natural environments. Time and length scale ratios are roughly $1 / 3$ and 1/10, respectively. Water levels and bed levels were measured along the cross-shore bed profile. In this paper we focus on tests 17 and 18: irregular waves (JONSWAP spectrum) with significant wave height of $0.16 \mathrm{~m}$ and a spectral peak period of 2 (Test 17) and 3 (Test 18) s.

\section{Computation orbital velocity time-series}

As shown in Figure 3 and in more detail in Nomden (2011), the existing formulae to compute orbital velocities from phase-averaged wave characteristics do not always give an accurate result, which strongly affects the predicted net transport rates. Since this paper aims to test the SANTOSS sand transport formula, we ideally use measured values. However, these data are not available for the Grasso cases. Instead we have developed an alternative method to compute orbital velocity time-series based on wave height, wave length and water depth. It involves three steps.

First, the skewness $\left(S k_{\eta}\right)$ and asymmetry $\left(A s_{\eta}\right)$ of the surface elevation are computed based on the Ursell (Ur) number. These parameters are defined in the following way:

$$
\begin{gathered}
S k_{\eta}=\frac{\overline{(\eta-\bar{\eta})^{3}}}{\overline{(\eta-\bar{\eta})^{2}}} \\
A s_{\eta}=\frac{\overline{H^{3}(\eta-\bar{\eta})}}{\overline{(\eta-\bar{\eta})^{2}}} \\
U r=\frac{3}{8} \frac{H_{s} k}{(k h)^{3}}
\end{gathered}
$$

where $\eta$ is the water surface elevation, $H$ the Hilbert transform, $k$ the wave number, $h$ the water depth and the overbar the time-average operator. Following Ruessink et al. (2012), we have combined $S k$ and $A s$ into the total (non-dimensional) non-linearity parameter $B$ and phase $\beta$,

$$
\begin{aligned}
& B=\sqrt{S k^{2}+A s^{2}} \\
& \beta=\tan ^{-1}\left(\frac{A s}{S k}\right)
\end{aligned}
$$

and derived empirical fits for $B$ (in the form of a Boltzmann sigmoid) and $\beta$ (tanh-function) as a function of the Ursell number, using data from the Grasso experiments 15-18. This has resulted in the following expressions (with the angles in degrees):

$$
S k_{\eta}=\frac{1.55}{1+\exp \left(\frac{-0.47-\log U r}{0.36}\right)} \cos \left[-90+90 \tanh \left(\frac{1.50}{U r^{0.53}}\right)\right]
$$




$$
A s_{\eta}==\frac{1.55}{1+\exp \left(\frac{-0.47-\log U r}{0.36}\right)} \sin \left[-90+90 \tanh \left(\frac{1.50}{U r^{0.53}}\right)\right]
$$

which fit the data reasonably well as can be seen in Figure 5. Measured asymmetry for cases 15 and 16 is predominantly positive (backward leaning waves), which is by definition not represented by Eq. (11) (maximum value equals 0 ).
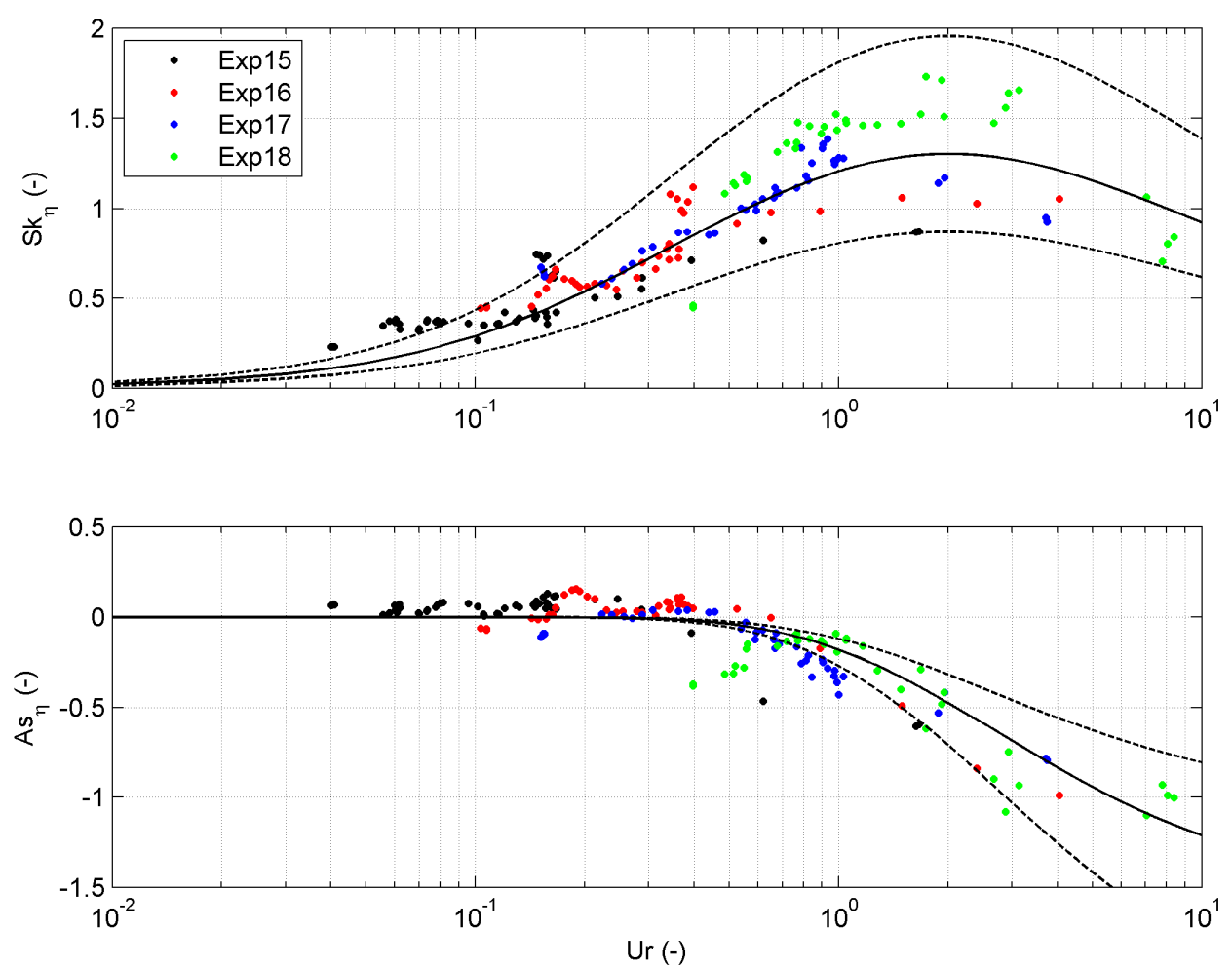

Figure 5. Comparison between measured (circles) and computed (solid lines) skewness (upper panel) and asymmetry (lower panel) of the water surface elevation as function of the Ursell number for Grasso cases 15 , 16,17 and 18. The dashed lines indicate a factor 1.5 difference with computed values.

The second step involves the computation of a water surface elevation time-series based on the computed skewness and asymmetry using the method of Abreu et al. (2010), which ensures a continuous time-series. In the third and final step the derived water surface elevation time-series is transferred into an orbital velocity time-series using the method described in Michallet et al. (2011):

$$
\tilde{u}=\frac{c}{h} \eta-\frac{c}{h^{2}}\left(\eta^{2}-\overline{\eta^{2}}\right)
$$

assuming shallow water and a locally constant wave form and celerity (time- and length-scales of changes in the wave shape are large compared to wave period and length).

\section{Model-data comparison}

Figure 6 shows that by calibration the computed wave heights agree well with the measurements. The lower panels show the bed level evolution during the experiments. Figure 7 shows the computed significant orbital velocities in the on- and offshore direction as well as the wave-averaged velocity 0.1 $\mathrm{m}$ above the bed. This figure shows that the orbital velocity amplitude, velocity skewness and return flow are generally higher for the longer wave period case 18 . The computed orbital velocity skewness peaks at around $x=20 \mathrm{~m}$ for Grasso case 17 with a value $R \approx 0.68$, whereas maximum skewness is $R$ $\approx 0.70$ at around $x=10 \mathrm{~m}$ for Grasso case 18 . 

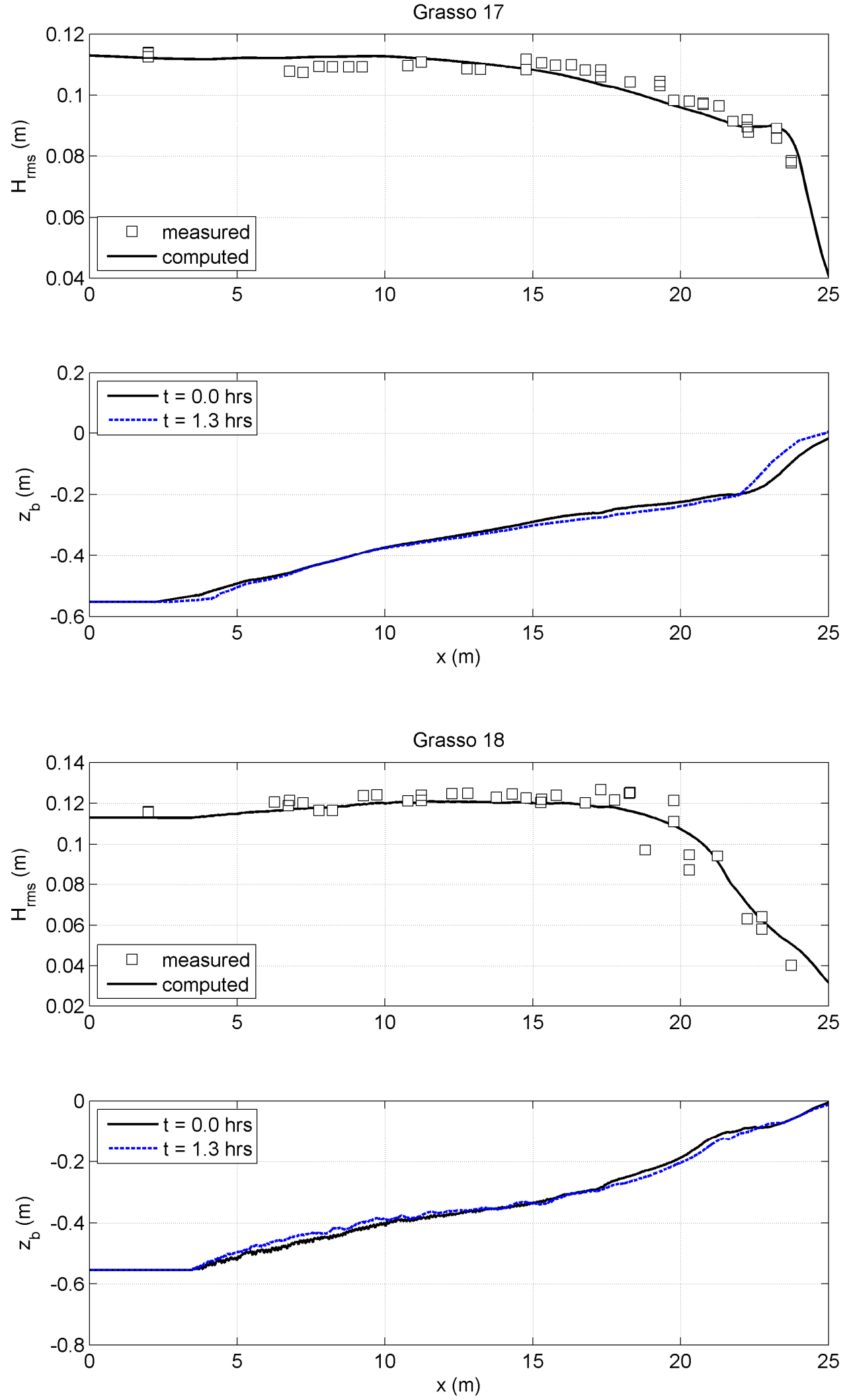

Figure 6. Measured (squares) and computed (solid lines) wave heights for the Grasso cases 17 (upper) and 18 (lower). Also shown are the bed level measurements that were used to determine the measured net transport rates. 

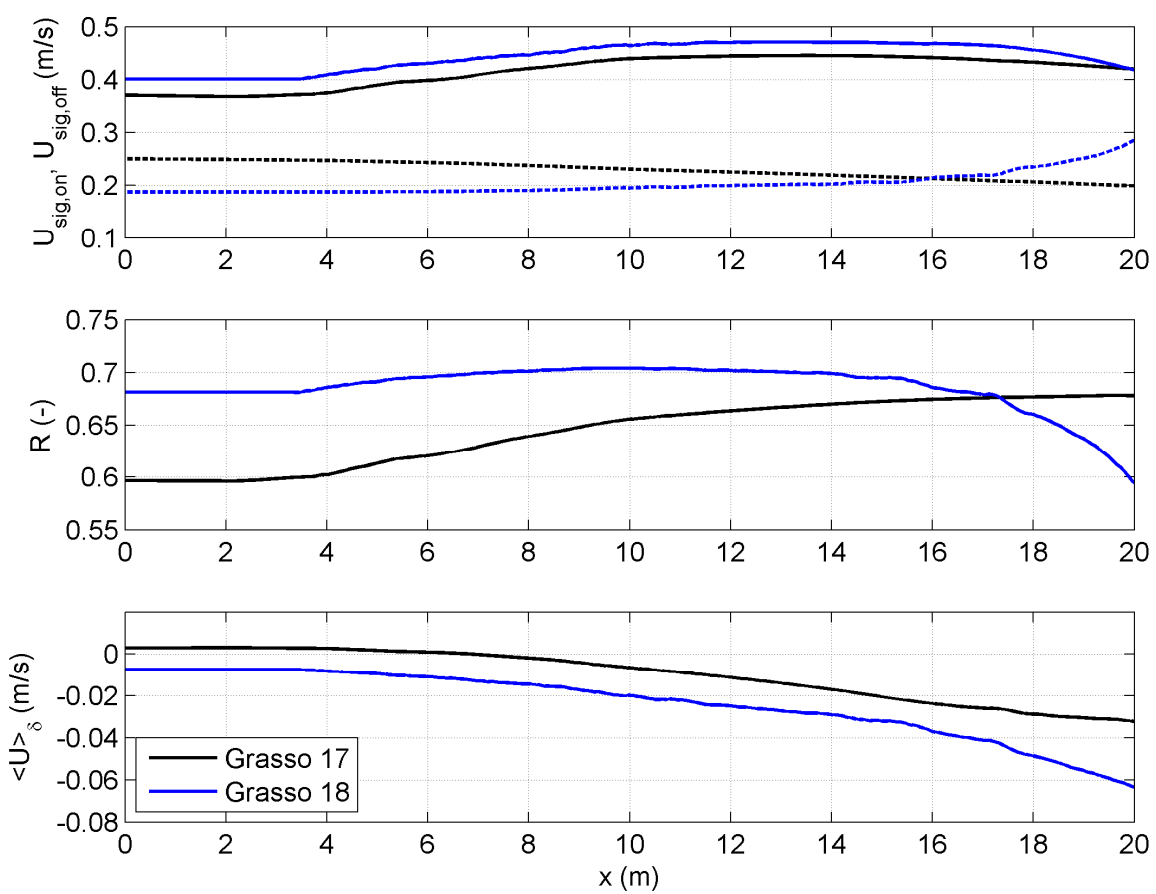

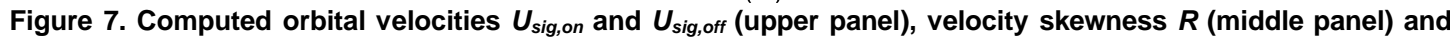
wave-averaged velocities at $\delta=0.1 \mathrm{~m}$ (lower panel) for Grasso cases 17 (black lines) and 18 (blue lines).

Figure 8 compares measured and computed total net transport rates. Note that we have re-scaled the ripple height computed by the SANTOSS formula for Grasso case 17, see later on. The measurements show onshore-directed (positive) net sand transport for case 17 and offshore-directed (negative) net sand transport for case 18. According to Grasso et al. (2011), this can be explained by phase-lag effects: sediment mobilized during the wave crest is transported by the following wave trough. Phase-lag effects were stronger for case 18 as the ripples were higher related to the longer wave period; maximum ripple heights were approx. $0.3 \mathrm{~cm}$ for case 17 and $1.0 \mathrm{~cm}$ for case 18 . Both the Van Rijn and SANTOSS formula reproduce the onshore net transport for the Grasso 17 case, although transport rates tend to be overpredicted, especially by the Van Rijn formula. The SANTOSS formula gives net offshore sand transport for the Grasso 18 case, as was measured. The Van Rijn model wrongly predicts the transport direction for this case, except for close to the shore $(x \approx 18-20$ $\mathrm{m}$ ), which is due to suspended load related to the offshore-directed undertow. Although both models account for phase-lag effects, the difference in model behaviour could be attributed to the fact the SANTOSS model is also validated using a large dataset of rippled-bed experiments, including cases with net offshore transport rates.

Figure 9 distinguishes between the near-bed, current-related suspended above the wave boundary layer and total transport as computed by the SANTOSS formula. (For clarity reasons we only show the mean of the two measured net transport rates that follow from integration the mass balance equation from the left- and right-hand side.) For case 17 the current-related suspended load is almost zero up to $x \approx 10 \mathrm{~m}$ and the total net transport is dominated by the onshore-directed transport due to wave nonlinearity, in line with the small undertow values (Figure 7) and the findings of Grasso et al. (2011). From here shoreward the undertow becomes stronger, suspended sand concentrations higher and orbital velocity skewness lower. At $x=20 \mathrm{~m}$ the onshore-directed near-bed transport and the currentrelated suspended load almost balance, resulting in a computed total net transport close to zero. This is not observed in the measurements, suggesting that the near-bed transport is underpredicted and/or the current-related suspended load is overpredicted. For case 18, these two contributors are in the same direction (offshore) and of the same order of magnitude up to $x \approx 10 \mathrm{~m}$. From hereon near-bed transport becomes onshore-directed, but as offshore-directed current-related suspended load dominates, the total computed net transport stays offshore-directed. This contradicts Grasso et al. who stated that the net transport was not controlled by the undertow alone, as the (computed) values were too small. Possibly, the UNIBEST-TC model overpredicts the undertow and sand concentrations, and does not reproduce velocity skewness and asymmetry correctly (as for the LIP cases, see Section 2). We have, however, no data to test this hypothesis. 

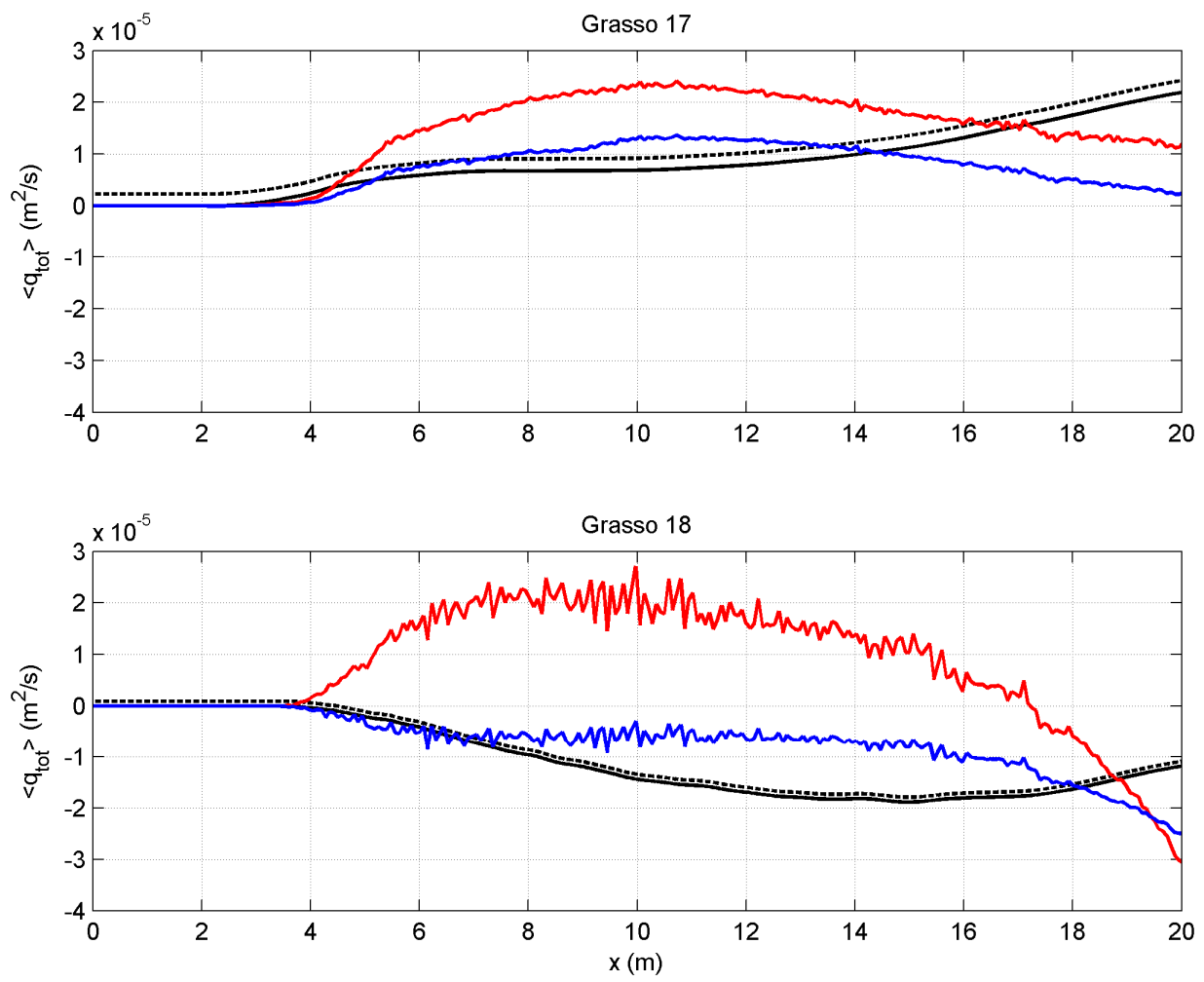

Figure 8. Comparison between measured and computed total net sand transport for Grasso case 17 (upper panel) and 18 (lower panel). Solid black lines: based integration mass balance equation from the right side; dashed black lines: based on integration mass balance equation from the left side; red lines: computed by the Van Rijn formula; blue lines: computed by the SANTOSS formula.
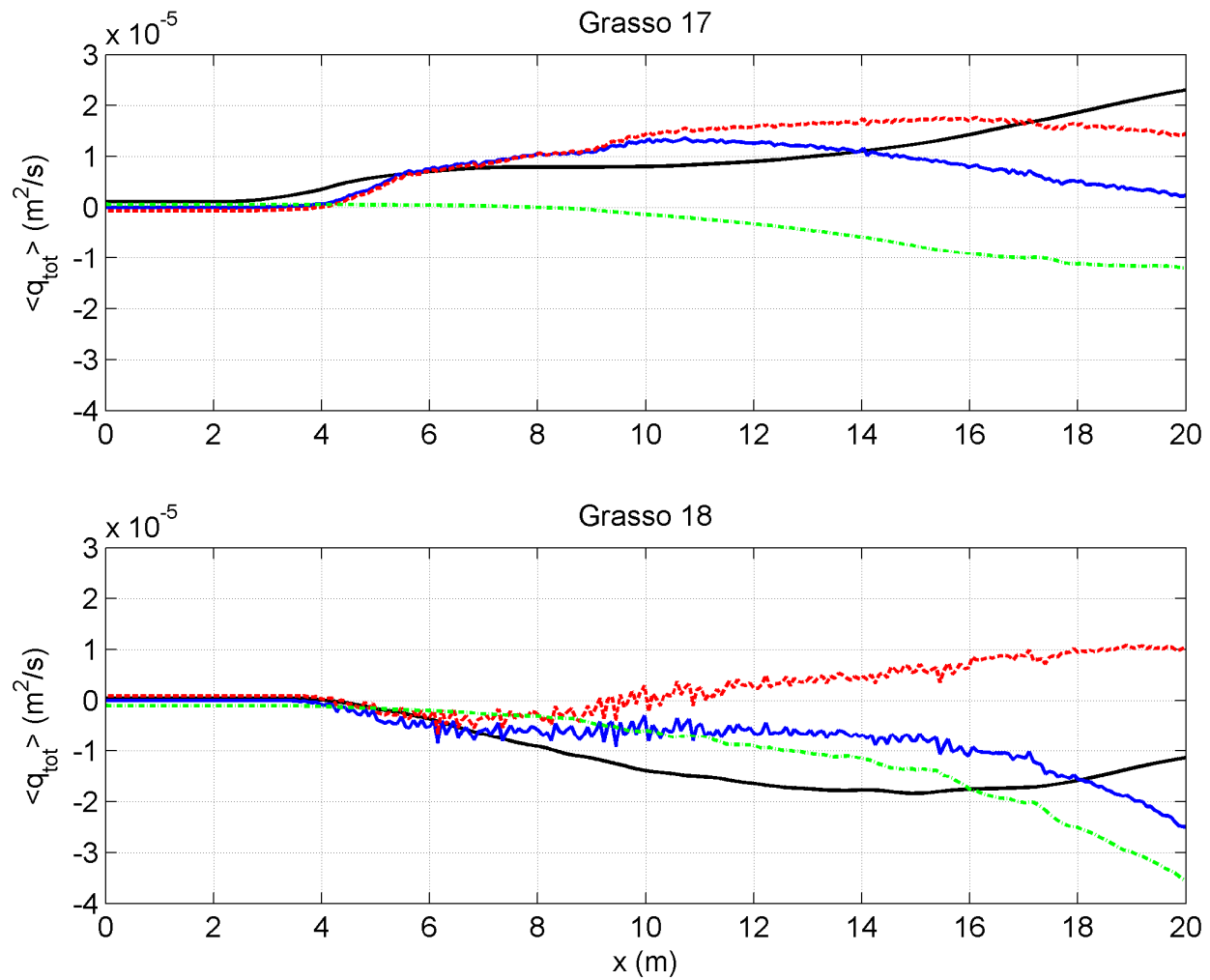

Figure 9. Measured total net sand transport (solid black lines) and the total (sold blue lines), near-bed (red dashed lines) and current-related suspended (green dashed-dotted lines) transport computed by the SANTOSS formula for Grasso cases 17 (upper panel) and 18 (lower panel). 
The importance of including phase-lag effects and correct predictions of ripples heights in order to get agreement with measured net transport rates is shown in Figure 10. Here we show measured net transport and net transport computed by the SANTOSS formula with all processes switched on (as in Figures 8 and 9), but without phase-lag effects and without ripple height scaling (for Grasso 17) and with ripple heights set to zero (for Grasso 18).
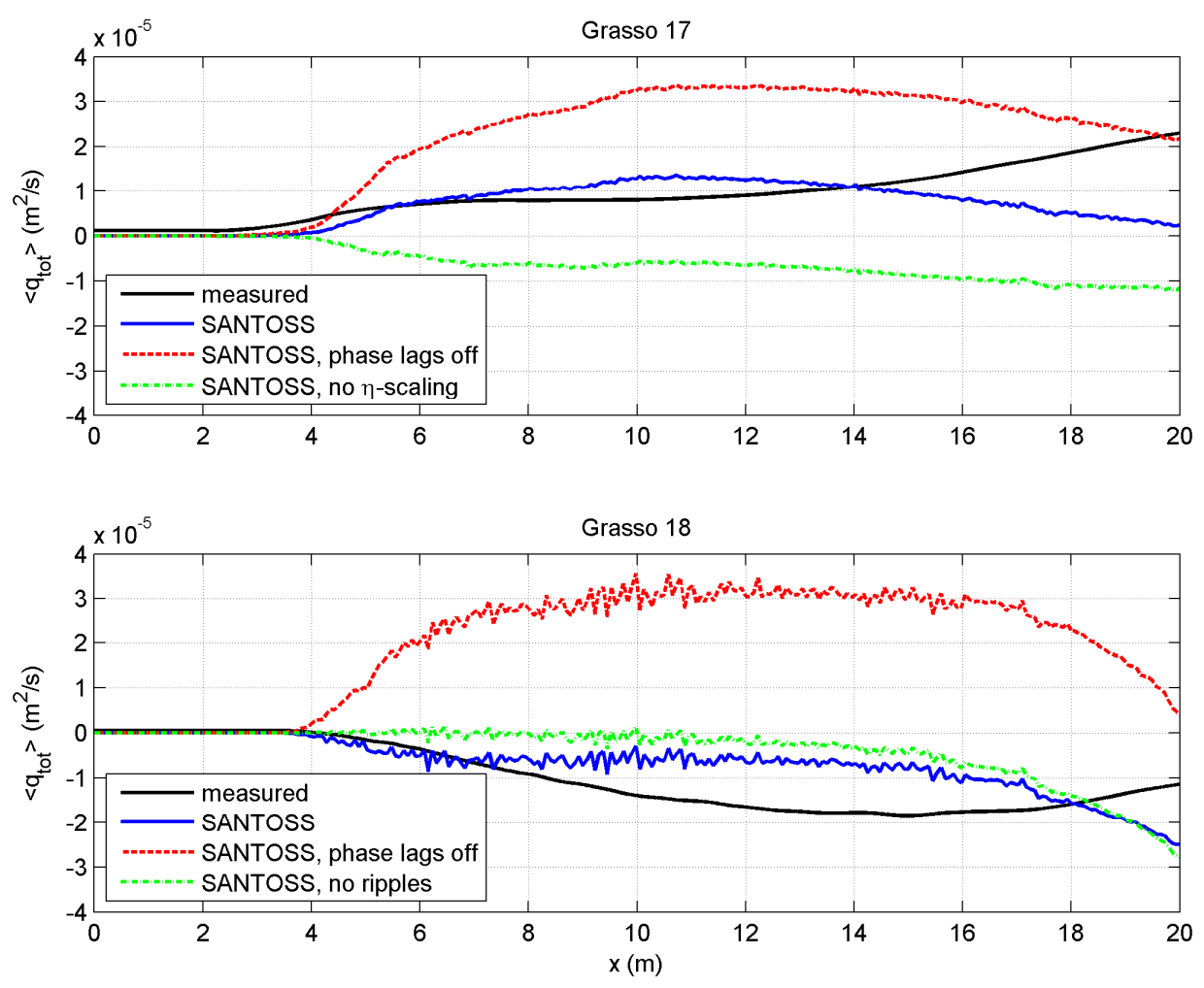

Figure 10. Measured total net sand transport (solid black lines) and total net transport computed by the SANTOSS formula with different parameter settings (other lines) for Grasso cases 17 and 18.

Accounting for phase-lag effects proves to be crucial: ignoring phase-lag effects results in large onshore-directed net transport rates, which correspond to a strong overprediction of measured values for case 17 and the wrong net transport direction for case 18. This is due to the near-bed transport contribution that is without phase-lag effects directed onshore, mainly due to the higher onshore orbital velocity peak compared to the offshore orbital velocity peak (velocity skewness).

The ripple predictor included in the SANTOSS transport formula is based on the work by O'Donoghue et al. (2006). This method is based on a large set of laboratory data from full-scale (periods $T>4 \mathrm{~s}$ ) laboratory experiments. In the Grasso experiments sediment consisting of large grains with low density was used. The used sediment in combination with the relatively short period $(T=2 \mathrm{~s})$ might explain the strong overprediction of ripple height for case 17. If we do not scale the computed ripple height with a factor of 0.3 , the phase-lag parameter $P \sim \eta /\left(w_{s} T\right)$ (with $w_{s}$ the sediment fall velocity, see Van der Werf, 2006; Ribberink et al., 2008) is too high, phase-lag effects are too strong, too much sediment is transferred from the onshore to the offshore wave cycle and computed net transport rates become strongly offshore-directed. The opposite applies for Grasso case 18 ran without ripples: computed suspension heights are lower, reflected in a reduction of the $P$ parameter by which the potential for offshore net transport decreases.

\section{CONCLUSIONS}

We have implemented and tested the new SANTOSS transport formula in the framework of the morphological modeling system UNIBEST-TC using data from in total 4 cases from the LIP and Grasso wave flume experiments. From this we conclude the following: 
1. A good prediction of orbital velocity skewness and asymmetry is crucial in order to reproduce measured net transport rates. The Ruessink et al. (2012) method compares reasonably well to the measured onshore and offshore velocity peaks for LIP 1B, but not for LIP 1C. For the Grasso cases there were no velocity data for comparisons, and therefore we developed a new orbital velocity formula with which we were able to reproduce measured net transport rates reasonably well.

2. The LIP cases with measured vertical profiles of wave-averaged velocities and suspended sand concentration offered the opportunity to distinguish between near-bed transport (wave- and current-related bedload and suspended load within the wave boundary layer) and current-related suspended load above the wave boundary layer. The near-bed transport is typically onshoredirected due to wave non-linearity, whereas current-related suspended load above the wave boundary layer is offshore-directed due to undertow. Both transport components peak at the breaker bar, where wave breaking generates large amounts of suspended sand. For the erosion test case LIP 1B, the onshore-directed near-bed transport is dominant offshore of the breaker bar, while the offshore-directed undertow transport dominates from the breaker bar onshore. Wave breaking is less intense for test case LIP 1C due to the lower wave height, and as a result net transport is onshore-directed along the profile, due to the dominant near-bed transport.

3. Both the Van Rijn (2007ab) and the SANTOSS transport formula produce transport rates that agree reasonably well with measured net transport rates outside the surf zone for LIP 1B. Both models do not work properly within the surf zone where the near-bed transport is strongly underpredicted.

4. The SANTOSS model is able to reproduce the onshore-directed net transport for Grasso case 17 and the offshore-directed net transport for Grasso case 18. The model results supports the hypothesis that this difference is due to phase-lag effects which are stronger for case 18 with larger ripples due to the longer wave period. Next to accounting for phase-lag effects, correct prediction of the presence and height of ripples is crucial in order to have reliable net transport predictions.

5. We recommend to further test and improve methods to compute orbital velocities and study the effects of wave breaking on sand transport processes (especially the wave-related suspended load).

\section{ACKNOWLEDGMENTS}

Florent Grasso is acknowledged for proving his data. This work has been partly carried out within the framework of the Deltares Strategic Research project Systeemgedrag Kust (project number 120.2359).

\section{REFERENCES}

Abreu, T., Silva, P.A., Sancho, F., and A. Temperville, 2010. Analytical approximate wave form for asymmetric waves. Coastal Engineering, 57(7), 656-667.

Grasso, F., Michallet, H., and E. Barthélemy, 2011. Sediment transport associated with morphological beach changes forced by irregular asymmetric, skewed waves. Journal of Geophysical Research, Vol. 116, C03020.

Michallet, H, Cienfuegos, R., Barthélemy, E, and F. Grasso, 2011. Kinematics of waves propagating and breaking on a barred beach. European Journal of Mechanics - B/Fluids, 30(6), 624-634

Nomden, H.G., 2011. SANTOSS sand transport model: Implementing and testing within the morphological model UNIBEST-TC. M.Sc. thesis, University of Twente, The Netherlands.

O'Donoghue, T., Doucette, J.S., Van der Werf, J. J. and J.S. Ribberink, 2006. The dimensions of sand ripples in full-scale oscillatory flows. Coastal Engineering, 53(12), 997-1012.

Ribberink, J. S., Van der Werf, J. J., O'Donoghue, T., and W.N.M. Hassan, 2008. Sand motion induced by oscillatory flow: Sheet flow and vortex ripples. Journal of Turbulence, 9(20), 1-32.

Roelvink, J.A., and A.J.H.M. Reniers, 1995. LIP 11D Delta Flume experiments, A data set for profile model validation. Report H2130, Delft Hydraulics, The Netherlands.

Ruessink, B.G., Ramaekers, G. and L.C. van Rijn, 2012. On the parameterization of the free-stream non-linear wave orbital motion in nearshore morphodynamic models. Coastal Engineering, 65, $56-63$ 
Ruessink, B.G., Kuriyama, Y., Reniers, A.J.H.M. Roelvink, J.A., and D.J.R. Walstra, 2007. Modeling cross-shore sandbar behaviour on the timescale of weeks. Journal of Geophysical Research, 112, F03010.

Sleath, J.F.A., 1987. Turbulent oscillatory flow over rough beds. Journal of Fluid Mechanics, 182, 369-409.

Van der A, D., Ribberink, J., Van der Werf, J., and T. O’Donoghue, 2010. New practical model for sand transport induced by non-breaking waves and currents. Proceedings of $30^{\text {th }}$ International Conference on Coastal Engineering, Shanghai, China.

Van der Werf, J.J., 2006. Sand transport over rippled beds in oscillatory flow. Ph.D thesis, University of Twente, The Netherlands.

Van Rijn, L.C., 2007a. Unified View of Sediment Transport by Currents and Waves, I: Initiation of Motion, Bed Roughness, and Bed-Load Transport. Journal of Hydraulic Engineering, 133(6): 649-667.

Van Rijn, L.C., 2007b. Unified View of Sediment Transport by Currents and Waves, II: Suspended Transport. Journal of Hydraulic Engineering, 133(6): 668-689.

Van Rijn, L.C., Tonnon, P.K. and D.J.R. Walstra, 2011. Numerical modelling of erosion and accretion of plane sloping beaches at different scales. Coastal Engineering, 58, 637-655. 